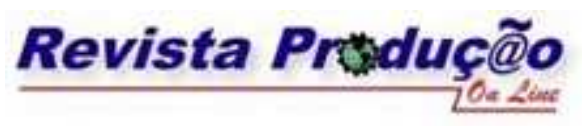

\title{
IMPLANTAÇÃO DE CONTROLE BASEADO NO SISTEMA DE EXECUÇÃO DA MANUFATURA (MES): ANÁLISE EM EMPRESA DE USINAGEM NO SETOR \\ AERONÁUtico
}

\section{IMPLEMENTATION OF CONTROL BASED ON MANUFACTURING EXECUTION SYSTEM (MES): ANALYSIS IN THE MACHINING COMPANY OF AERONAUTICS SECTOR}

\section{Marcelo Leite Vanderlei}

Eng. Mestre / Professor

Curso de Tecnologia da UNIP - Universidade Paulista

eng.mlv@gmail.com

Jorge Muniz Junior

Eng. Dr./Professor

Departamento de Engenharia de Produção, FEG/UNESP

jorgemuniz@feg.unesp.br

\section{Fernando Augusto Silva Marins}

Eng. $\mathrm{PhD} /$ Professor

Departamento de Engenharia de Produção, FEG/UNESP

fmarins@feg.unesp.br

\section{Gilberto Walter Arenas Miranda}

Eng. Dr./Professor

Departamento de Engenharia Mecânica, UNITAU - Universidade de Taubaté

gilware@terra.com.br

\section{RESUMO}

O Sistema de Execução da Manufatura (MES - Manufacturing Execution System) é uma ferramenta de controle da produção aplicada no chão-de-fábrica que permite visualizar e monitorar processos em tempo real, fornecendo informações que levam a uma melhor eficiência operacional. Este trabalho apresenta uma pesquisa exploratória, realizada em uma empresa de usinagem e montagem de médio porte, tendo o objetivo analisar a implantação do MES para auxiliar a tomada de decisão referente à produção. $O$ trabalho também compara dois sistemas de controle de produção: o MES com o sistema realizado de forma manual (planilhas eletrônicas) utilizado antes de sua implantação. As informações sobre implantação foram coletadas por meio de questionário e validadas em grupo de discussão com os 


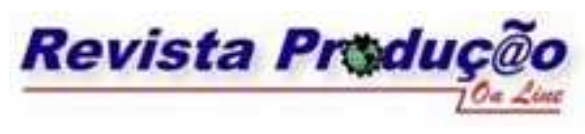

entrevistados e acadêmicos. Entre os resultados alcançados, identificaram-se: i) as vantagens do MES em relação ao sistema manual, ii) a eficácia da implantação, iii) melhoria dos resultados operacionais, iv) pontos positivos e negativos da implantação e aplicação.

Palavras-chave: sistema de execução da manufatura, MES, chão-de-fábrica, tempo real, tomada de decisão.

\begin{abstract}
MES (Manufacturing Execution System) is a tool for production control used in shop-floor that allows you to view and monitor processes in real time, providing information that leads to better operational efficiency. This paper presents an conducted in a company of machining and assembly, with objective to analyze the implementation of MES to assist in decision making concerning the management of production. The study also compares two systems of production control; the MES with the manual (spreadsheet) used before to implementation. The information basis to analysis the implementation was collected through questionnaire evaluation, validated by a discussion group. The results was: i) the benefits of MES, ii) the effectiveness of implementation, iii) improving operating results, iv) positive and negative effects of deployment and application.
\end{abstract}

Keywords: MES, manufacturing execution system, shop-floor, on time, decision making.

\title{
1 INTRODUÇÃO
}

A indústria permite de modo direto e abrangente a distribuição de riquezas por meio da geração de emprego e renda à população, fortalecendo a economia como um todo. $\mathrm{O}$ desenvolvimento econômico, num cenário de globalização, gera novos problemas e novas demandas às empresas (WAGNER et al., 2008). Muitas consideram a importância do acompanhamento do desempenho da manufatura em suas estratégias competitivas. Assim sendo, a importância deste trabalho é evidenciar que por meio da utilização de ferramentas da Tecnologia da Informação, mais especificamente, de sistema de controle da manufatura, pode-se melhorar a produtividade da empresa, baseado em informações das operações, para a tomada de decisão do gestor da produção.

As empresas passaram a utilizar, cada vez mais, sistemas informatizados para melhorar os resultados, em razão de sua maior capacidade de processar e possibilitar o compartilhamento do conhecimento da empresa. Porém, muitos fatores contribuem para o não aproveitamento de informações: comunicação deficiente, qualificação profissional insuficiente, sistemas informatizados mal implantados, dimensionamento errado de recursos, 


\section{Revista Produç@o}

falta ou excesso de controles. Murback, Paiva e Carvalho (2006) afirmam que qualquer estratégia adotada por uma empresa deve ser desenvolvida incluindo uma estrutura de controle.

Embora a Tecnologia da Informação seja difundida no ambiente fabril, em muitas empresas, ainda o controle da produção é feito de forma manual, dificultando o entendimento da realidade produtiva. Já em indústria de produção contínua (petroquímica, alimentícia, siderurgia) o monitoramento em tempo real é previsto desde o projeto da planta (SALATIEL et al., 2008). Neste tipo de indústria, a cultura do monitoramento dos processos produtivos em tempo real é tradicional, porque requer que o tempo de detecção e correção de nãoconformidade seja realizado em poucos minutos.

Nesse contexto, o objetivo do presente artigo é analisar a implantação do sistema de controle da produção, denominado Sistema de Execução da Manufatura (MES). Como objetivos específicos o artigo: compara o MES com o sistema de controle baseado em planilhas eletrônicas, descreve as vantagens e desvantagens de ambos os sistemas de controle e avalia as contribuição do MES em relação a fatores de desempenho tradicionais (qualidade, produtividade, custos, pontualidade).

O estudo é delimitado a uma empresa de usinagem e montagem de peças estruturais para aeronaves, situada no Vale do Paraíba (SP), que iniciou a implantação do sistema de controle MES em 2007. A avaliação com usuários do sistema foi realizada em 2009.

O gestor tem influência direta na tomada de decisão e necessita de ferramentas confiáveis para auxiliá-lo nesse processo. Ansoff e McDonnell (1993 apud MURBACK; PAIVA; CARVALHO, 2006) levantam a importância de medir o desempenho da produção para analisar a situação, mudar metas, reavaliar estratégia e reprogramar ações. Nesse sentido, este trabalho contribui na análise de um sistema de controle que auxilia o gestor com relação a tomada de decisão e a tratamento de dados de produção de forma eficiente em relação às práticas tradicionais, visando a eliminação de fontes de desperdício no chão-de-fábrica.

A seguir é apresentada a fundamentação teórica referente ao levantamento bibliográfico. A Seção 3 aborda o método de pesquisa adotado, o objeto de estudo (empresa pesquisada) é apresentado na seção 4. Os resultados da pesquisa são discutidos na seção 5 e finalmente as conclusões são apresentadas na seção 6.

\section{REVISÃO BIBLIOGRÁFICA}




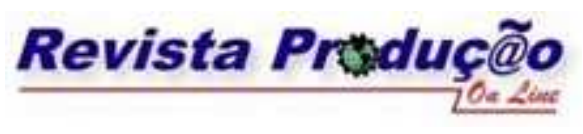

Associação Brasileira de Engenharia de Produção - ABEPRO Universidade Federal de Santa Catarina - UFSC www.producaoonline.org.br

ISSN 1676 - 1901 / Vol. IX/ Num.IV/ 2009

Os fundamentos teóricos os quais serviram de base para esse trabalho, se relacionam com os conceitos: Sistema de Execução da Manufatura (MES), Eficiência Global dos Equipamentos (OEE), Produtividade, Participação das pessoas em projetos de TI e Método de Pesquisa.

\subsection{SISTEMA DE EXECUÇÃO DA MANUFATURA}

MES - Manufacturing Execution System ou Sistema de Execução da Manufatura, o qual tem uma contribuição da área de Tecnologia da Informação (TI), que é uma ferramenta de tomada de decisão, baseada em dados obtidos em tempo real de pontos chaves do processo. Será relacionado o MES com o Sistema de Gestão Empresarial (ERP - Enterprise Resources Planning) que tem como principal objetivo a integração de todos os dados e informações advindos do setor financeiro, recursos humanos, qualidade, logística, produção, produto, vendas, entre outros (KLETTI, 2007; KUCGANT, 2008).

Para tratar as informações geradas e processadas nesses processos, utiliza-se de vários meios da Tecnologia da Informação (TI), que pode ser entendida como os meios utilizados pelas empresas produtivas para alavancar e potencializar o processo de criação e desenvolvimento de capacitação tecnológica (VALLE, 1996). É frequente o argumento que TI é um importante fator de aumento da produtividade e redução de custos. O MES é uma ferramenta proveniente da TI (BESSEN, 2002; KAGAN, 1994; KOTHA, SWAMIDASS, 2000 apud LORENTE; RODRIGUES; DEWHURST, 2004). Atualmente, esforços para o entendimento de que as práticas de TI melhoram o desempenho empresarial estão sendo realizadas (DAVENPORT; MARCHAND; DICKSON, 2004 apud MARTINS et al., 2008).

Segundo Martins (2008), os gestores esperam que a TI melhore o desempenho por meio de quatro maneiras: a) Melhorar a eficiência das operações; b) Melhorar as comunicações, apoiando o funcionamento dos processos; c) Facilitar as tomadas de decisões, por meio de disponibilização de informações; d) Apoiar a inovação no desenvolvimento de novos produtos e serviços. A norma ABNT NBR ISO 9001:2008 no item 0.2 cita "que para uma organização funcionar de maneira eficaz, ela tem que identificar e gerir numerosas atividades interligadas". A norma ABNT NBR 15100:2002 (sistema de qualidade aeroespacial) enfatiza no item 0.2 ; c; obtenção de resultados de desempenho e eficácia de processo e no item d; melhoria continua de processos baseada em medições objetivas. Ambas 


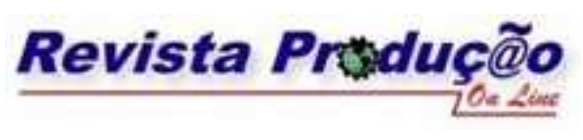

Associação Brasileira de Engenharia de Produção - ABEPRO Universidade Federal de Santa Catarina - UFSC www.producaoonline.org.br ISSN 1676 - 1901 / Vol. IX/ Num.IV/ 2009

as normas (a empresa estudada possuía as duas certificações) incentivam a adoção de práticas de mensuração que podem ser facilitadas pelo uso do MES.

Em uma empresa industrial, o modelo de negócios é baseado em três níveis: planejamento, execução e controle. No nível de planejamento, é onde se realiza o sequenciamento das ordens de produção. O nível de execução deve receber as ordens de produção, enviar informações sobre o andamento dos trabalhos. Na execução, os procedimentos são feitos manualmente, utilizando-se de papéis, formulários e planilhas eletrônicas, muitas vezes sujeitas a falhas. O nível de controle recebe as informações sobre as ordens de produção e coordena as atividades (SHIRASUNA, 2008; PADRÃO JR; ALVES FILHO; LANNA, 2002).

O MES foi criado para ser aplicado para monitorar a execução dos processos no chãode-fábrica em tempo real, integrando o planejamento com o controle gerencial (SHIRASUNA, 2008; KUCGANT 2008; VINHAIS, 1998; SEIXAS FILHO, 2007). Um sistema de coleta de dados e informações ajuda na tomada de decisão (BRAH; LIM, 2006). A coleta de dados pode ser automática ou manual. De acordo com as informações fornecidas do momento e do histórico, permite ao gestor tomar medidas corretivas para reduzir e/ou eliminar problemas nas células de produção, aumentando o valor agregado das operações. Para obter a funcionalidade, é necessário implantar sistemas de aquisição de dados, conhecido por PIMS - Plant Information Management Systems - que recuperam os dados do processo em fontes distintas, os armazenam em um banco de dados único. Então disponibilizam por meio de diversas ferramentas, como o MES (CARVALHO et al., 2005).

O MES trabalha relacionado a diversas atividades da produção, tais como: ordens de produção, fluxo de materiais, qualidade, matéria- prima, padrões de operação, operador, manutenção, entre outros. Funciona integrado com o ERP da empresa trabalhando de maneira complementar. O MES compreende doze funcionalidades: planejamento detalhado, gerenciamento de recursos, registro e visibilidade dos recursos, gerenciamento de documentos, gerenciamento de materiais, análise de desempenho, gerenciamento de mão-deobra direta, gerenciamento de manutenção, gerenciamento do processo, gerenciamento da qualidade, coleta de dados e registros e por fim, rastreabilidade e genealogia do produto (KLETTI, 2007; SALATIEL, 2008; VINHAIS, 1998). Seixas Filho (2007), afirma que quem define as funcionalidades do MES deve ser alguém que compreende muito bem os processos do nível de produção. 


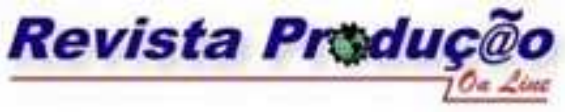

Associação Brasileira de Engenharia de Produção - ABEPRO Universidade Federal de Santa Catarina - UFSC www.producaoonline.org.br

ISSN 1676 - 1901 / Vol. IX/ Num.IV/ 2009

Consideram-se potenciais benefícios com a aplicação do MES: melhoria dos prazos de entrega, redução do tempo de produção, redução de inventário em processo, melhora do desempenho dos recursos, informação em tempo real sobre as ordens de produção, melhora da qualidade das decisões, redução de custo, elimina e ou reduz controles em papel, melhora da utilização dos recursos, melhora da qualidade, entre outros (KLETTI, 2007; PADRÃO JR; ALVES FILHO; LANNA, 2002). Empresas que utilizam o MES apontaram que houve um aumento de $70 \%$ de produtividade e a lucratividade aumentou de $86 \%$ para $350 \%$ em um período de três anos, conforme Shirasuna (2008).

Para o MES funcionar é necessário criar uma convergência entre a automação industrial e TI da organização e pode ser absorvida pela indústria para o aumento da produtividade e redução de custos, conforme (MACNAB 2008; VINHAIS, 1998). O fator decisivo é proporcionar a visibilidade das operações para a tomada de decisão. É comum em empresas que não utilizam o MES, processar as informações manualmente a cada MES. Dessa forma, se perde a agilidade e se tem apenas a visão do passado (SILVA JR, 2008; SOUZA, 2008; PADRÃO JR; ALVES FILHO; LANNA, 2002; BARTHOLOMEW, 2004). Ainda Bartholomew (2004) afirma que para que as empresas continuem crescendo, é necessário um sistema de informação em tempo real, devido a enorme volatilidade do mercado.

Segundo Silva Jr (2008), obtinham as informações do chão-de-fábrica, por meio de relatórios mensais manualmente. Quando a informação estava disponível, era apenas uma visão contábil porque já não se podia tomar nenhuma providência. Portanto, torna-se necessário um sistema de coleta de informações, a fim de entender as deficiências. Informação, visibilidade de processo, qualidade dos dados e controle não são mais opcionais - tornam-se vitais (LATTARO, 2008). Neste ponto, Nakajima (1989), afirma que o levantamento e o diagnóstico da situação para possibilitar uma avaliação correta. Infelizmente, em muitas empresas o registro destes dados são precários e não parecem ser confiáveis. Alguns encaram o tempo consumido com registros como plenamente dispensável ou mesmo inúteis. Assim, torna-se difícil detectar as diversas formas de perdas.

At the same time, there is A evolução tecnológica está cada vez mais rápida e o setorincreasingly rapid technologic de TI está cada vez mais provendo mecanismos que fornecem medições de produtividade de modo mais rápido e acurado, melhorando a comunicação, facilitando a implantação de ferramentas, sistemas e aplicações com esse fim 


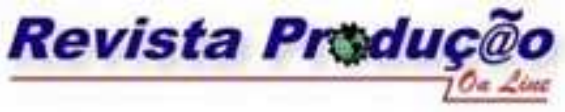

(LORENT, RODRIGUEZ e DEWHURST, 2004). Para ganhar uma vantagem competitiva, as empresas must constantly keep abreast of, and devem acompanhar constantemente e improve on, their technology. melhorar sua tecnologia. Not only A habilidade de responder rápida e efetivamente, com o foco no cliente, se tornou uma característica de competitividade para muitas indústrias (NEVES e SANTOS, 2008). thing in common: all require a differen

O benefício da utilização de um MES é de primeiro momento, a facilidade de obter dados do chão-de-fábrica e tomar decisão mais rapidamente, para diminuir perdas. O desafio maior, porém, é analisar os dados e perceber se algum recurso produtivo está fornecendo dados coerentes. É muito comum devido falhas de treinamento, ou mesmo falta de comprometimento, os dados informados apresentarem algum tipo de problema que pode levar a uma decisão equivocada.

Esses casos são mais comuns quando as obtenções dos dados não são automatizadas, ou seja, são obtidos manualmente. Mas em processos não contínuos, a colaboração da equipe torna-se fundamental. Lobato (2002), afirma que a TI tem grande impacto tanto sobre a estratégia de liderança em custo, quanto na estratégia de diferenciação. Ainda, o mesmo autor reforça que o seu impacto se dá sobre os custos das atividades da cadeia de valores.

\subsubsection{PORQUE USAR O MES}

O ERP foi projetado para gestão de alto nível, e por isso se mantiveram distantes do mundo real do chão-de-fábrica (BARTHOLOMEW, 2006). Como o ERP não controla o chão-de-fábrica, a produção tem de controlar as etapas de manufatura e gerar indicadores de desempenho de diversas maneiras. Por a gestão de produção determinar as atividades relacionadas ao planejamento empresarial, manufatura, controle e programação da produção, engenharia, suprimentos, logística, melhoria da produtividade, tecnologias e equipamentos, qualidade, meio ambiente (NEVES; SANTOS, 2008), torna-se necessário um maior controle do processo de produção das empresas (SOUZA et al., 2008; SHIRASUNA, 2008; KUCGANT 2008; VINHAIS, 1998). Obter ferramentas que facilitem ao gestor da produção tomar decisão é importante para o resultado global da empresa. Por esse motivo, também é abordado alguns pontos sobre integração do MES com ERP, administração industrial, conhecimento e estratégia. Geralmente, o ERP não possui aplicativo referente ao controle de chão-de-fábrica e os dados obtidos são genéricos e de difícil acesso. Isso acontece porque o ERP é projetado com foco financeiro (pedidos, compras, recebimentos, pagamentos, estoque, 


\section{Revista Produç@̃ @o}

custo), em detrimento a outros processos gerenciais (qualidade, produção, manutenção, segurança).

Oliveira, T. (2008), aponta outras dificuldades, tais como: ordens de produção sendo encaminhados por papeis, inventários com diferenças, ordens de manutenção abertas após horas de linha parada, pouco controle sobre horas trabalhadas, entre outros. As empresas que implantaram o ERP em seus negócios, começam a se dar conta que as possibilidades de ganho se tornam mais raras e que as possibilidades mais claras se encontram na linha de produção (EGREJA, 2008).

Vários trabalhos têm tratado da implantação de ERP enfocando suas vantagens, dificuldades, sucessos, impactos nas pessoas e no negócio, possível aumento da competitividade (AL-MASHARI; AL-MUDIMIGH, 2003; BENDOLY; SCHOENHERR, 2005, CERRI, 2004 apud NEVES; SANTOS, 2008). Porém, conforme afirma Neves e Santos (2008), tem-se observado uma lacuna que distancia os sistemas ERP e as tecnologias utilizadas no chão-de-fábrica, referente à troca de informações. Esse vazio é evidenciado pela falta de conhecimento do que acontece nos processos em tempo real. Por isso, a necessidade da integração do chão-de-fábrica, de forma simples, instantânea e confiável, com o sistema ERP é fundamental à melhoria dos processos produtivos (FERNANDES, 2006 apud NEVES; SANTOS, 2008; SALATIEL, 2008).

A Figura 1, apresenta o cenário mais usual nas empresas, em relação a integração do ERP com o chão-de-fábrica.

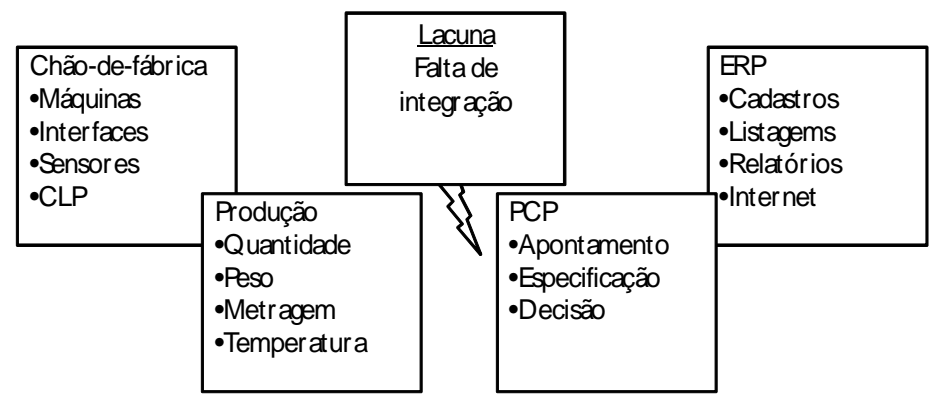

Figura 1: Cenário inicial: vazio separando a gestão da produção do chão-de-fábrica.

Fonte: NEVES; SANTOS (2008).

Conforme Neves e Santos (2008), a integração do chão-de-fábrica com o ERP passa a ser de grande importância, objetivando ganhar qualidade da informação gerada e 


\section{Revista Produç@o}

compartilhada de forma eficiente e rápida. Desta forma, a gestão da produção ganha confiabilidade, com redução de erro e rapidez da geração da informação para demais áreas. A lacuna mostrada na Figura 1 é preenchida com a ferramenta MES que atua entre o nível operacional e empresarial (SHIRASUNA, 2008; VINHAIS, 1998).

O MES é projetado para integrar os dados da operação com o ERP (KATZ, 2007) e garante um gerenciamento mais eficiente, possibilitando a tomada de decisão com base em informações mais confiáveis (NEVES; SANTOS, 2008; PADRÃO JR; ALVES FILHO; LANNA, 2002; VINHAIS, 1998). Neves e Santos (2008) listam alguns benefícios: i) Consolida o planejamento e o mapeamento para a execução de todas as etapas de produção; ii) Conecta o processamento de pedidos com os controles dos sistemas da produção; iii) Otimiza os processos de produção; iv) Democratiza a informação; v) Integra as informações da produção e permite visualizar a fábrica como um todo e em tempo real. A integração do chão-de-fábrica com o ERP (Entreprise Resouces Planning) passa a ser crucial e visa permitir que os diversos sistemas e processos operem de forma paralela e convergente, nos diversos níveis hierárquicos da organização (NEVES; SANTOS, 2008; PADRÃO JR; ALVES FILHO; LANNA, 2002; VINHAIS, 1998; CARVALHO, 2005). Sem a integração, é impossível considerar que se está obtendo o máximo de desempenho, pois sempre haverá retrabalho e desperdício de tempo, além de grande probabilidade de erro por falha humana. (GAIDZINSKI, 2003 apud NEVES; SANTOS, 2008).

Para que implantado de modo consistente, deve seguir as orientações concebidas dentro das normas ISA 95 que tem como premissa a integração entre os sistemas corporativos e os de manufatura (SEIXAS FILHO, 2007). Novas formas de coleta de informação em tempo real estão em fase de avaliação (VAZ, 2008). Sistemas como o MES permitem a análise contínua da condição dos equipamentos e disponibiliza informação do produto em todos os pontos do processo, no tempo certo e no lugar certo, sendo a chave para a produtividade (VAZ, 2008; SOUZA, 2008; SALATIEL, 2008; PADRÃO JR; ALVES FILHO; LANNA, 2002).

O uso da TI passa a ter papel fundamental nas organizações, possibilitando melhor percepção das mudanças, maior flexibilidade e agilidade nas operações (FERREIRA; ALVES, 2005 apud NEVES; SANTOS, 2008). Lobato (2002) afirma que por meio da TI, tem-se a transformação dos dados encontrados em grande volume no nível operacional, para informações, fundamentais no processo de decisão do nível estratégico da organização. 


\section{Revista Produç@o}

Associação Brasileira de Engenharia de Produção - ABEPRO

Universidade Federal de Santa Catarina - UFSC www.producaoonline.org.br

ISSN 1676 - 1901 / Vol. IX/ Num.IV/ 2009

\subsection{PRODUTIVIDADE}

A competição, a necessidade de conquistar novos mercados e atender demandas, melhores margens, a melhoria da qualidade e da produtividade tem levado as empresas a investirem em processos que melhorem a gestão da produção. (NEVES; SANTOS, 2008). A necessidade de mudanças nas organizações não deixa de existir (MONTANARI; PILATTI; SCANDELARI, 2006). Um sistema de medição correto e a gestão com parâmetros-chave contribuem para aumentar a produtividade tanto na área como na planta (HANSEN, 2006; MONTANARI; PILATTI; SCANDELARI, 2006). Waurzyniak (2006) destaca que com sistemas de TI que integram as operações "com a visualização das estações de trabalho podese em tempo real ver exatamente o que está acontecendo - tempo decorrido, parada, perdas, ganhos, velocidade - tudo sobre a produtividade".

\subsection{PARTICIPAÇÃO DAS PESSOAS EM PROJETOS DE TI}

As mudanças ambientais internas e externas afetam fatores que são críticos para uma organização. Segundo Lobato (2002), cada empresa deveria identificar regularmente, quais áreas são os fatores que contribuem para o seu sucesso, reavaliando as metas e os objetivos durante os períodos de mudança, de acordo com as informações no momento. Procura-se, portanto, redução de desperdício e ganhos no processo produtivo, promovendo aprendizado e conhecimento pelo envolvimento das pessoas, diretamente envolvidas no processo produtivo, de modo que tenham mais controle sobre o mesmo (MUNIZ JR, 2007). Os objetivos devem ser quantificados em metas que se querem atingir; a estrutura consiste na organização formal das pessoas, dos recursos materiais e do tempo, necessários às atividades e responsabilidades; a comunicação envolve o processo pelo qual ideias e sentimentos são transmitidos de pessoa para pessoa, de pessoa para grupo, ou de grupo para grupo; o treinamento é a busca da habilidade em atividades de produção, por meio de simulação de situações semelhantes, propiciando aos membros o uso de ferramentas e técnicas que os auxiliem na melhoria de seu trabalho.

Considerando um projeto que envolve as pessoas e tecnologia, Pitassi e Leitão (2002) dizem que cabe a TI, ao disponibilizar mais informação sobre o ambiente, tem o poder de melhorar a qualidade da decisão gerencial aplicada no processo de mudança organizacional e acelerá-la. Muniz Jr (2007) salienta o papel dos supervisores e operários como chave para a 


\section{Revista Produç@o}

melhoria contínua e para o processo de inovação na fábrica, e enfatiza a importância do trabalho em grupo e do incremento das responsabilidades desses grupos. Pode-se levantar a hipótese de que exista entre os funcionários uma demanda reprimida de utilização de computadores e a operação dos terminais alavanca a aceitação do projeto (PADRÃO JR; ALVES FILHO; LANNA, 2002), no caso, a implantação de um sistema MES.

\section{MÉTODO DE PESQUISA}

Segundo Miguel (2007), uma pesquisa pode ter os seguintes objetivos: familiarizar com um fenômeno ou conseguir uma nova compreensão; apresentar informações sobre uma dada situação, grupo ou entidade; verificar a freqüência com que algo ocorre ou como se liga a outros fenômenos; verificar uma hipótese de relação causal entre variáveis. Diehl e Tatim (2004), afirmam que as ciências sociais aplicadas constituem uma área do conhecimento e de atuação profissional polivalente, conjugando o domínio de várias disciplinas. A engenharia de produção se insere nesse contexto. Neste trabalho, a interação dos conhecimentos se refere às seguintes áreas: estratégia empresarial, gestão da produção, qualidade e tecnologia da informação.

Utilizando a classificação de Diehl e Tatin (2004), esta pesquisa pode ser caracterizada de acordo com o Quadro1.

Quadro 1: Classificação da pesquisa.

\begin{tabular}{|l|l|}
\hline Bases lógicas da investigação & Fenomenológico \\
\hline Abordagem do problema & Qualitativo \\
\hline Objetivo geral & Exploratória \\
& Descritivo \\
\hline Propósito & Avaliação de resultados \\
& Avaliação formativa \\
& Proposição de planos \\
\hline Procedimento técnico & Ex-post-facto \\
\hline
\end{tabular}

Base lógica de investigação: fenomenológico devido ser um estudo de observação dos acontecimentos da implantação do MES, relacionando com a visibilidade das operações, influências sobre as pessoas e percepção sobre o valor agregado ao negócio, alterando o ambiente técnico e social. 


\section{Revista Produç@o}

Abordagem do problema: se refere à falta de controle no processo industrial. Caracteriza-se por ser pesquisa qualitativa onde os resultados se baseiam na análise das respostas do questionário de avaliação e dos comentários do Grupo de Discussão.

Objetivo geral: se caracteriza por ser exploratório, por tentar tornar mais conhecido as dificuldades de implantação e aplicação do MES combinado com o indicador OEE. Também se caracteriza por ser descritivo, apresentando técnicas de coleta de informações sistematicamente (questionário).

Propósito: contempla três tipos de pesquisa: i) avaliação de resultados, por apresentar uma série de resultados qualitativos entre uma situação anterior e posterior; ii) avaliação formativa, por se tratar de uma pesquisa que visa contribuir com o aperfeiçoamento de sistemas de controle em produção discreta; iii) propósito de planos, que tem como um dos principais objetivos dessa pesquisa solucionar, ou, propor controle de desempenho, a padronização, dados e informações, para a tomada de decisão.

Procedimento técnico: se caracteriza por ser ex-post-facto, por se tratar de um estudo realizado depois dos fatos, neste caso, os resultados da implantação e aplicação do MES.

\subsection{QUESTIONÁRIO ADOTADO}

Para a fundamentação teórica da abordagem do problema quanto às análises qualitativa e quantitativa, torna se necessária aprofundar-se na questão do processo da coleta de dados por meio dos questionários. A coleta de dados é um processo importante para garantir que a análise dos resultados seja o mais preciso possível e que a interpretação seja plausível. Segundo Diehl e Tatim (2004), existem diversas ferramentas de coleta de dados que podem ser empregadas, sendo que devem ser escolhidas e aplicadas pelo pesquisador, conforme o contexto. Nesta pesquisa, as formas de coleta foram: observação, questionário e entrevista. Conforme Hill, A. e Hill, M. (1998), as perguntas podem ser abertas, fechadas ou múltipla escolha.

Perguntas abertas permitem ao informante responder livremente. As perguntas fechadas, o informante escolhe uma resposta entre duas opções; sim ou não. Nas perguntas de múltipla escolha, são fechadas, mas com várias opções de respostas. A pesquisa deve ter um objetivo principal e um ou mais objetivos específicos. O objetivo principal tem como 
finalidade testar a hipótese geral da pesquisa. Os objetivos específicos testar hipóteses mais específicas.

Quadro 2: Estrutura do questionário.

\begin{tabular}{|c|c|c|}
\hline QUESTIONÁRIO & PROPÓSITO & OBJETIVOS DA PESQUISA \\
\hline Tema & $\begin{array}{l}\text { Título do questionário, objetivo e } \\
\text { identificação do pesquisador. }\end{array}$ & Não aplicado \\
\hline $\begin{array}{l}1^{\circ} \text { Parte: uma pergunta } \\
\text { aberta }\end{array}$ & Informações sobre o pesquisado. & Classificar os pesquisados. \\
\hline $\begin{array}{l}2^{\circ} \text { parte: quatro perguntas } \\
\text { abertas }\end{array}$ & $\begin{array}{l}\text { Coletar informações sobre o } \\
\text { sistema de controle de produção } \\
\text { manual. }\end{array}$ & $\begin{array}{l}\text { Específico: comparar o controle } \\
\text { de produção manual com o } \\
\text { MES. }\end{array}$ \\
\hline $\begin{array}{l}3^{\circ} \text { parte: sete perguntas } \\
\text { abertas }\end{array}$ & $\begin{array}{l}\text { Coletar informações sobre a } \\
\text { implantação do MES. }\end{array}$ & $\begin{array}{l}\text { Principal: avaliar a eficácia da } \\
\text { implantação do MES. }\end{array}$ \\
\hline $\begin{array}{l}4^{\circ} \text { parte: } 9 \text { perguntas } \\
\text { fechadas com } 5 \text { opções de } \\
\text { respostas (tabela). }\end{array}$ & $\begin{array}{l}\text { Coletar dados relacionando } \\
\text { desempenho com o uso do MES. }\end{array}$ & $\begin{array}{l}\text { Específico: avaliar o MES com } \\
\text { os fatores de sucesso da } \\
\text { empresa. } \\
\text { A definição e escolha foram } \\
\text { determinadas em função dos } \\
\text { indicadores principais da } \\
\text { empresa, os quais eram a base } \\
\text { do programa de participação } \\
\text { dos resultados, rentabilidade, } \\
\text { fidelidade do cliente e clima } \\
\text { organizacional. }\end{array}$ \\
\hline
\end{tabular}

Foram enviados 30 questionários em novembro de 2008 por correio eletrônico, a um grupo de pessoas que participaram da implantação do MES, sobre o tema da pesquisa: "Com o sistema de monitoramento de produção em tempo real, ficou mais simples e claro onde estão os problemas que afetam o desempenho da organização”. Destes, nove questionários foram respondidos, representando $30 \%$ do total. Na Tabela 1, podem-se observar as funções que foram representadas na devolução do questionário. A representatividade por setor que está representada na Tabela 2.

Tabela 1: Representatividade dos pesquisados por função. 


\begin{tabular}{lc}
\hline Função & Frequência \\
\hline Operador Máquina & 1 \\
Coordenador Produção & 3 \\
Analísta PCP & 1 \\
Supervisor Logística & 1 \\
Engenheiro Vendas & 1 \\
Gerente Vendas & 1 \\
Gerente TI & 1 \\
\hline Total & $\mathbf{9}$ \\
\hline
\end{tabular}

Tabela 2: Representatividade dos pesquisados por setor.

\begin{tabular}{lc}
\hline Setor & Frequência \\
\hline Comercial & 2 \\
Logística & 2 \\
Produção & 4 \\
TI & 1 \\
\hline Total & $\mathbf{9}$ \\
\hline
\end{tabular}

Para a análise dos resultados, utilizou-se a técnica Análise e Interpretação dos Resultados formulada por Tatim e Diehl (2004) que consiste em construir teorias a partir do significado e das explicações que os entrevistados atribuem aos eventos pesquisados.

Em linhas gerais, tanto na pesquisa qualitativa, quanto na quantitativa, o processo de organização dos dados pode ser resumido nas seguintes etapas: i) seleção: consiste na verificação detalhada dos dados coletados, a fim de detectar erros, evitando informações confusas e incompletas; ii) classificação: consiste na ordenação dos dados, de acordo com determinado critério, os quais orientam sua divisão de classes ou categorias; iii) codificação: no caso do uso do método quantitativo, consiste na atribuição de símbolos (letras ou números), a fim de transformar os dados em elementos quantificáveis para posterior tratamento estatístico; iv) representação: apresentação dos dados de forma que se facilite o processo de inter-relação entre eles e sua relação com a hipótese ou pergunta da pesquisa. 


\section{Revista Produç@o}

\section{CASO ESTUDADO: IMPLANTAÇÃO DO MES}

A empresa estudada é de porte médio, de acordo com a classificação do BNDES (2008), com faturamento anual de oito milhões de dólares, de capital misto nacional-alemã. Situada na região do Vale do Paraíba, na cidade de Taubaté, SP.

Sua produção é de pequenos lotes sob encomenda, onde possui 12 centros de usinagem $\mathrm{CNC}$ de 3 e 5 eixos, 10 bancadas de ajustagem e 12 bancadas de montagem. $\mathrm{O}$ negócio principal da organização é de fornecer prestação de serviços em usinagem e montagem. A partir de maio de 2007 o sistema começou a rodar, ou seja, os apontamentos passaram a ser coletados por meio do MES. Como resultado imediato, a visibilidade dos equipamentos passou a ser disponibilizados (Figura 3).

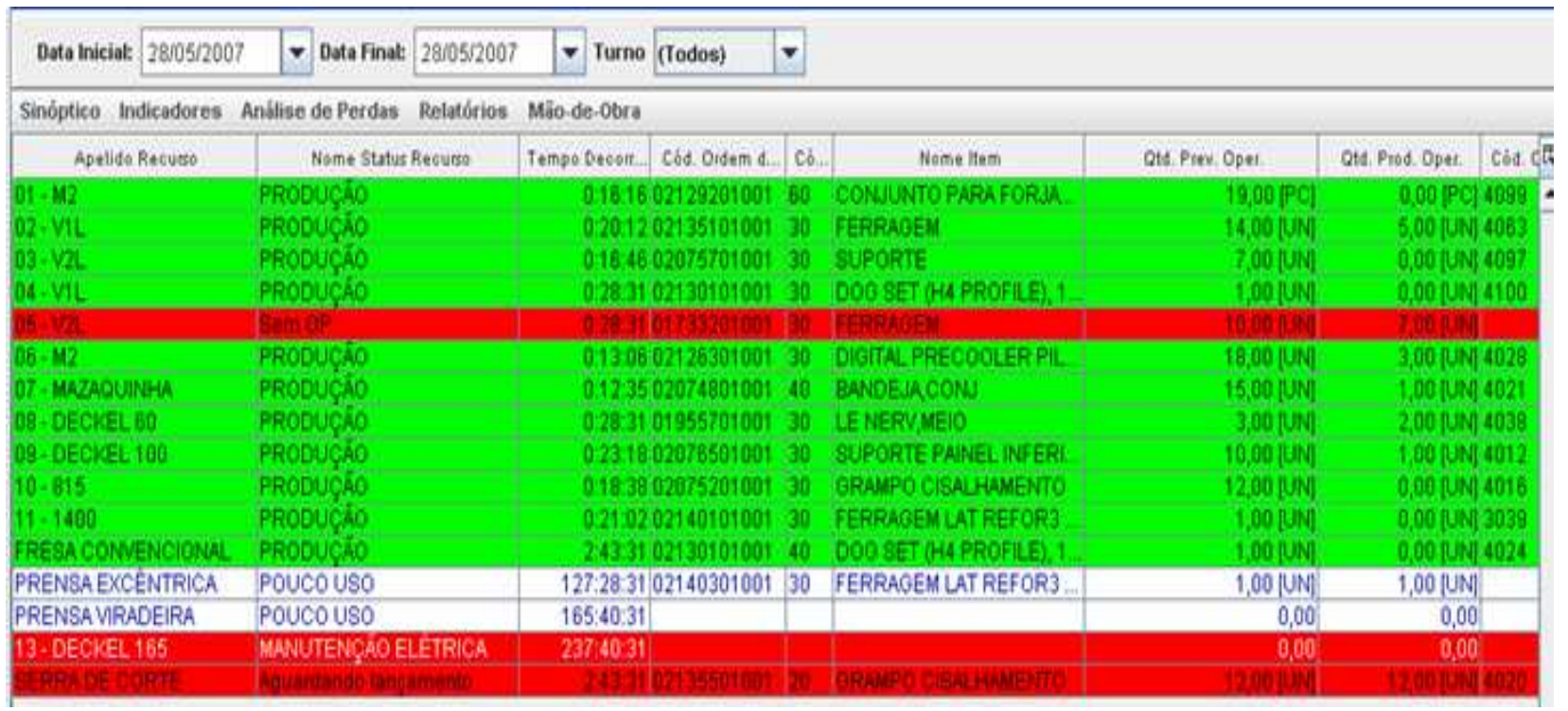

Figura 2: Sinótico dos equipamentos no Monitoramento da Produção

Foi considerada desde o início da implantação, a participação efetiva dos funcionários, principalmente da produção, para garantir a veracidade das informações inseridas. Foram realizados eventos que antecederam a implantação do software, com o objetivo de sensibilizar as pessoas sobre a importância de seu entendimento sobre o monitoramento para identificar as perdas durante os processos produtivos.

O enfoque foi de criar e manter um ambiente de trabalho e um clima organizacional que levassem a excelência operacional, à plena participação, ao crescimento pessoal e da organização. Os treinamentos focaram: OEE, TPM, Kaizen e ferramentas da qualidade. 


\section{Revista Produç@o}

Correa e Miranda (2008) afirmaram que: o projeto colabora muito com o desenvolvimento profissional dos funcionários, pois é necessário conhecer tecnicamente os materiais e os processos nos quais eles estão envolvidos, aplicar técnicas estatísticas, desenvolver o lado observador, participar das atividades, exporem suas opiniões (CORREA; MIRANDA, 2008).

\section{ANÁLISE DOS RESULTADOS}

Apresentam-se os resultados da pesquisa de campo, levantados por meio de questionários. Após a análise dos resultados, foi criado um grupo de discussão, formado por pessoas que participaram do projeto e apresentado os resultados, a fim de validarem a pesquisa e também obter mais dados a fim de complementar a pesquisa. Inicialmente foi realizada a análise das respostas referente às perguntas abertas relacionadas à avaliação da implantação do MES. Na sequência são discutidas as respostas consolidadas das perguntas fechadas, relacionadas aos fatores de sucesso da empresa. No final, é apresentada uma tabela comparativa entre o MES e com o sistema manual (planilha eletrônica).

\subsection{QUESTIONÁRIO ABERTO}

A seguir, serão apresentadas as respostas, referente o período que antecedeu a implantação do MES, onde era utilizado o sistema de controle manual. Essas perguntas estão relacionadas com um dos objetivos principais desta pesquisa, que compara o sistema de apontamento de produção manual com o MES.

\section{Pergunta 1: “Como era o apontamento de produção antes do MES?”}

Parte dos entrevistados respondeu que não havia sistema de apontamento, outra parte respondeu que os dados eram apontados em planilhas eletrônicas. Ainda outros responderam que os apontamentos eram realizados no sistema de informações gerenciais. Conclui-se que o sistema que antecedeu o MES era pouco conhecido e incompleto. Não havia um padrão de apontamento e que o sistema de controle era impreciso.

Pergunta 2: “Qual é sua percepção sobre o desempenho da produção e montagem?” 


\section{Revista Produç@o}

A análise das respostas leva a entender que de maneira predominante, todos tinham a percepção de que o desempenho era baixo, desconhecido e de difícil medição. $\mathrm{O}$ desempenho era desconhecido, sem parâmetros, sem padrão. Conclui-se que os padrões de desempenho eram imprecisos e em alguns casos, inexistentes.

Pergunta 3: “Em sua opinião, os equipamentos de produção eram utilizados adequadamente?"

Oito responderam categoricamente que os equipamentos não eram usados adequadamente. Citaram perdas de tempo devido falta de planejamento, excesso de setup. Não se sabia onde atuar nos problemas, a mão-de-obra e equipamentos eram subutilizados, perdia-se tempo em atividades que não agregavam valor. Conclui-se que a utilização dos recursos produtivos era baixa, devido a excesso de paradas e falta de gestão sobre paradas.

Pergunta 4: “As perdas de produção e montagem eram identificadas e tratadas de maneira a eliminar a(s) causa(s) raíz(es)? Por favor, explique.”

A sistemática de solução de problemas não era direcionada às causas, pois não havia informação com qualidade para embasar a análise. No sistema manual o controle de qualidade não analisava as causas de refugo, tendo o foco na reposição da peça. Em relação a retrabalho, havia ações para reduzir ou eliminar as causas. Conclui-se que os problemas voltavam a ocorrer, tornando o processo instável e ineficaz.

Pergunta 5: “Em sua opinião, o sistema de monitoramento foi implantado de maneira adequada? Por favor, explique.”

Dos nove pesquisados, cinco afirmaram que o projeto foi bem implantado e consideraram o processo bem desenvolvido. As respostas dos outros quatro pesquisados, levam a percepção de que a implantação teve algumas falhas, causada por desconhecimento da ferramenta e complexidade, entre outros. Ressaltaram que a auto-estima das pessoas aumentou, pois muitos passaram a ter contato com o computador, ao apontar os dados. Conclui-se que a implantação foi eficaz, mas que a faltou uma visita em uma empresa que estaria utilizando o MES, antes da implantação, pois dificultou o entendimento prévio do sistema. 


\section{Revista Produç@o}

Pergunta 6: "Qual sua opinião sobre a medição da produção para identificar as perdas, antes e depois do MES?”

Evidenciou-se que antes do MES, não havia uma mensuração do problema e nem direcionamento. Com o MES, a visibilidade das perdas foi facilitada, bem como sua mensuração, permitindo priorizar os esforços de acordo com a importância. Antes do MES, não conseguiam ver o que ocorria na produção. Como não sabiam priorizar, escolhiam um problema e tentavam resolver, mas sem direção. Depois do MES, priorizar os problemas ficou fácil, pois o sistema mostrava, por meio dos relatórios e indicadores. Conclui-se que o MES forneceu uma visibilidade e direcionamento que tornou a gestão mais eficaz e eficiente.

\section{Pergunta 7: “O sistema é simples de operar e útil para a empresa?”}

Todos reconheceram que o sistema era simples de operar e de grande utilidade, sustentado por treinamentos de qualificação do MES. É uma ferramenta simples, poderosa e útil por causa da visibilidade que proporciona aos gestores. Também é considerada muito importante para a empresa, por ser valorizado pelos clientes. O MES deixou de ser utilizado em setembro de 2007 e foi retomado a partir de maio de 2008, por determinação da diretoria. Como o treinamento dos usuários-chave havia sido bem realizado, a retomada foi tranquila. Concluise que o MES é uma ferramenta que facilita a gestão da produção, por ser simples útil e reconhecida pela direção, usuários e clientes.

\section{Pergunta 8: “Quais os benefícios que o sistema proporcionou na empresa?”}

Evidenciou-se que os benefícios foram: agilidade, monitoramento em tempo real, identificação da causa-raiz, indicadores, redução de desperdício, visibilidade, rápida intervenção dos responsáveis nos problemas, estratificação das paradas, histórico, integração, informações, dados estatísticos, facilidade para tomada de decisão, controle total da produtividade, melhoria da pontualidade, melhoria da eficiência, fortalecimento do espírito de equipe, melhor planejamento de férias, entre outros. Conclui-se que o sistema impactou positivamente na empresa.

Pergunta 9: “Na sua percepção, quem se beneficiou com o sistema?” 


\section{Revista Produç@o}

Levou-se a conclusão de que o MES beneficiou a empresa, funcionários e clientes. A empresa por causa do aumento da satisfação dos clientes e redução de custos. Os funcionários devido aos novos conhecimentos adquiridos (OEE, MES, ferramentas da qualidade, estratégia). Os clientes, decorrente do cumprimento dos prazos e acompanhamento dos pedidos.

Pergunta 10: “Recomendaria o uso do sistema em outras corporações?”

O MES obteve aprovação total e que recomendariam o sistema para outras empresas. Conclui-se que a confiabilidade do MES junto aos usuários é alta.

Pergunta 11: “O que faria de diferente para melhorar os benefícios do sistema?”

Considera-se que a ferramenta MES deve ter suas informações mais divulgadas no chão-defábrica, promover treinamento e capacitação contínua, intensificar a conscientização do objetivo principal de identificar perdas e estender a mesma a outros processos da empresa que não sejam somente produtivos. Recomendariam que o MES fosse manuseado por um especialista, com dedicação exclusiva, de modo a manter o sistema íntegro.

\subsection{QUESTIONÁRIO FECHADO}

A Tabela 3 mostra os dados consolidados da parte do questionário fechado, onde se avalia a contribuição do MES na organização, sob o ponto de vista dos pesquisados.

Tabela 3: Consolidação das perguntas fechadas.

\begin{tabular}{|l|ccccc|}
\hline O MEScontribuiu para a melhoria da(o)... & $\begin{array}{c}\text { Muito } \\
\text { Pior }\end{array}$ & Pior & Indiferente & Melhor & $\begin{array}{c}\text { Muito } \\
\text { melhor }\end{array}$ \\
\hline Qualidade? & $0 \%$ & $0 \%$ & $33 \%$ & $56 \%$ & $11 \%$ \\
Produtividade? & $0 \%$ & $0 \%$ & $0 \%$ & $56 \%$ & $44 \%$ \\
Desempenho? & $0 \%$ & $0 \%$ & $0 \%$ & $56 \%$ & $44 \%$ \\
Qusto? & $0 \%$ & $0 \%$ & $22 \%$ & $56 \%$ & $22 \%$ \\
Pontualidade? & $0 \%$ & $0 \%$ & $0 \%$ & $44 \%$ & $56 \%$ \\
Desenvolvimento dos processos de engenharia de manufatura? & $0 \%$ & $11 \%$ & $33 \%$ & $44 \%$ & $11 \%$ \\
Capacitação técnica dos envolvidos? & $0 \%$ & $0 \%$ & $33 \%$ & $56 \%$ & $11 \%$ \\
Relacionamento com os clientes? & $0 \%$ & $0 \%$ & $11 \%$ & $67 \%$ & $22 \%$ \\
Resultado global da empresa? & $0 \%$ & $0 \%$ & $0 \%$ & $89 \%$ & $11 \%$ \\
\hline
\end{tabular}




\section{Revista Produç@o}

A Tabela 3 mostra a consolidação das perguntas fechadas do questionário de avaliação referente os fatores de sucesso da empresa, chama a atenção para o fato de que o MES não contribuiu e até mesmo piorou, de acordo com a pesquisa. No caso da qualidade e capacitação técnica dos envolvidos, 1/3 dos entrevistados avaliou que a contribuição do MES foi indiferente e no fator custo, $1 / 5$ dos entrevistados também avaliaram da mesma forma. No desenvolvimento dos processos de engenharia de manufatura, $44 \%$ responderam que piorou ou não teve influência com a utilização do MES contra 55\% que avaliaram positivamente. Finalmente relacionado com a satisfação do cliente, $11 \%$ responderam que não houve mudança. Portanto, para futuros trabalhos de pesquisa, sugere-se que se direcione nestes pontos, para esclarecer os motivos que impedem o pleno benefício que o sistema pode atender.

Os fatores de sucesso da empresa melhoraram significativamente com o uso do MES. Porém alguns resultados apontam que o MES piorou ou teve contribuição nula, em alguns fatores (qualidade, desempenho, custo, processos, capacitação e relacionamento com clientes). Esses resultados podem ser uma direção de pesquisa para futuros trabalhos.

Com base nas respostas dos questionários e dos comentários do Grupo de Discussão, foram relacionados dados que levam a comparar os sistemas de apontamento de produção: manual (antes) com o MES. Esta comparação é um dos objetivos específicos desta pesquisa. O Quadro 3 mostra a comparação dos dois sistemas.

Quadro 3: Comparação do controle de produção Manual x MES.

\begin{tabular}{lll}
\hline CONTROLE & \multicolumn{1}{c}{ VANTAGENS } & \multicolumn{1}{c}{ DESVANTAGENS } \\
\hline & & \\
& & Apontamento manual descontínuo; \\
& & Sem interface com ERP; \\
& & Sem controle em vários processos; \\
& Baixo custo de investimento; & Sem conceitos de produtividade; \\
Baixo custo de operação; & Sem visibilidade; \\
Apontamento em planilha eletrônica; & Não considerava tempo padrão; \\
Apontamento em cadernos; & Difícil medir melhoria; \\
Formulário em papel; & Não controlava paradas; \\
& Personalizado; & Não havia rastreabilidade; \\
& Monitoramento por meio de observações no & Não identifica e mensura perdas; \\
& Não fornece dados para análise; \\
& local referente a um determinado momento; $;$ & Difícil priorização dos esforços; \\
& Causas raízes não eram identificadas; \\
& Sem histórico; \\
& Difícil estabelecimento de metas; \\
& Controle e informação obsoletam; \\
& Sem controle em tempo real, dificultando \\
\hline
\end{tabular}


análise e decisão;

Foco em refugo;

\begin{tabular}{ll}
\hline Identifica paradas, perdas, processos; & \\
Permite priorizar problemas; & \\
Simples; & \\
Eficaz; & \\
Melhora a produtividade; & \\
Redução do ciclo da operação; & Alto custo de investimento; \\
Redução de paradas; & Médio custo de operação; \\
Redução de retrabalhos; & Requer conhecimentos específicos para \\
Beneficia o cliente, empresa e envolvidos; & parametrizar (industrial, TI); \\
Visibilidade em tempo real; & Requer interface com ERP; \\
Facilidade no resgate do histórico; & Requer investimentos em TI; \\
Tomada de decisão assertiva; & Requer treinamentos em capacitação (OEE, \\
Informações claras e objetivas; & indicadores, ferramentas da qualidade, \\
Aumenta a capacitação; & finanças); \\
Fácil estabelecimento de metas; & Requer procedimento operacional padrão; \\
Melhora a sinergia; & Requer aumento da conscientização; \\
Útil; & Requer apoio da alta administração; \\
Aumenta a rentabilidade; & Requer auditoria; \\
Permite excelente nível de detalhamento; & Requer direcionamento estratégico, tático e \\
Padronização das operações; & operacional; \\
Melhora a pontualidade; & \\
Melhora a disciplina; & \\
Fornece base para desenvolvimento de novos & \\
processos; & \\
Permite entendimento da dinâmica da & \\
produção. & \\
& \\
\hline
\end{tabular}

\section{CONCLUSÕES}

O objetivo principal de análise da implantação, apresentado na discussão dos resultados (seção 5), indicou que a implantação gerou resultados satisfatórios para a empresa segundo os envolvidos no dia-a-dia. Convém destacar que a empresa já trabalha com o sistema de controle MES a três anos.

O objetivo específico de avaliar o uso do MES com os fatores de sucesso da empresa: qualidade, produtividade, desempenho operacional, custos, pontualidade, desenvolvimento de processos, capacitação técnica dos envolvidos, relacionamento com o cliente e resultados gerais da empresa, é atendido pela análise de conteúdo das respostas conforme apresentado na Seção 5 (Tabela 3). Fica evidenciado que o uso do MES aumentou o desempenho operacional.

O objetivo específico de comparar o uso da ferramenta MES no chão de fábrica para controlar a produção, por meio da coleta de dados e disponibilidade das informações em 


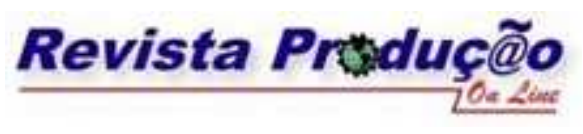

Associação Brasileira de Engenharia de Produção - ABEPRO Universidade Federal de Santa Catarina - UFSC www.producaoonline.org.br

ISSN 1676 - 1901 / Vol. IX/ Num.IV/ 2009

tempo real, com um sistema de apontamento realizado com planilhas eletrônicas, de forma manual, que antecedeu sua implantação, descrevendo as vantagens e desvantagens dos dois sistemas, é atendido pela análise de conteúdo das respostas consolidado no Quadro 3.

No decorrer da pesquisa identificou-se que a implantação do MES deve ser mais discutida. Para futuras pesquisas sugere-se: estudar a aplicação do MES em empresas de outros setores, para avaliar outras formas de aplicação, benefícios, padronização de procedimentos (norma ISA S95), os impactos causados pela utilização de tecnologia da informação em processos manuais, onde o trabalhador não é tão familiarizado com computadores.

\section{REFERENCIAS}

ABNT - ASSOCIAÇÃO BRASILEIRA DE NORMAS TÉCNICAS. NBR 15100, Rio de Janeiro, set. 2002.

ABNT - ASSOCIAÇÃO BRASILEIRA DE NORMAS TÉCNICAS. NBR ISO 9001, Rio de Janeiro, nov. 2008.

BARTHOLOMEW, D. Getting real with real time. Industry Week, n. 253, p. 34-36, mai. 2004.

BARTHOLOMEW, D. Where's the Magic? Suport for lean, improved visibility into operations drive investment in plant-floor technology. Industry Week, n. 255, p. 40-43, jul. 2006.

BNDES. Classificação de porte de empresa, carta circular nr. 62/02. Disponível em:

<http://www.bndes.gov.br/clientes/porte/porte.asp>. Acessado em: dez. 2008.

BRAH, S. A.; LIM, H. Y. The effects of technology and TQM on the performance of logistics companies. International Journal of Physical Distribution \& Logistics Management, Middletown, v. 36, n. 3, 2006, p. 192-209.

CARVALHO, F. B. DE et al. Sistemas PIMS - Conceituação, usos e benefícios. Tecnologia em Metalurgia e Materiais, São Paulo, v. 1, n. 4, p. 1-5, abr.-jun. 2005.

CORREA, L. A.; MIRANDA, G. W. A. Aumento da produtividade com apontamento da produção, monografia, Taubaté, UNITAU, 2008.

DIELH, A. A.; TATIM, D. C. Pesquisa em ciências sociais aplicadas: métodos e técnicas. São Paulo, Prentice Hall, 2004.

EGREJA, L. R. Conectando..., Controle e Automação, ano 11, n. 143, p. 44, 2008.

FERREIRA, F. P. Análise da implantação de um sistema de manufatura enxuta em uma empresa de autopeças, dissertação, Taubaté, UNITAU, 2004. 


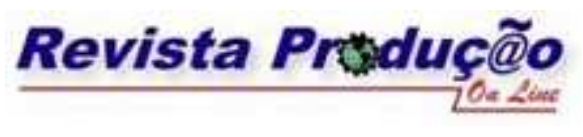

HANSEN, R. C. Eficiência global dos equipamentos - uma poderosa ferramenta de produção/manutenção para o aumento dos lucros. Porto Alegre, Bookman, 2006.

HILL, M. M.; HILL, A. A construção de um questionário, WP 98/11, Dinamia, 1998.

KATZ, J. Building a bridge to ERP, Industry Week, p. 45, fev. 2007.

KLETTI, J. (ORG) Manufacturing execution system - MES. Springer, Mosbach, 2007.

KUCGANT, M. Quando começou a integração entre automação e informação? Controle e Automação, ano 11, n. 143, p. 86-89, 2008.

LATTARO, P. Sob nova gestão, Controle e Automação, ano 11, n. 143, p. 53, 2008.

LOBATO, D. M. Administração Estratégica: uma visão orientada para a busca de vantagens competitivas. Rio de Janeiro, Editoração, 2002.

LOBATO, D. M.; MOYSÉS FILHO, J.; TORRES, M. C. S.; RODRIGUES, M. R. A. Estratégia de empresas. Rio de Janeiro, FGV, 2003.

LORENT, A. R. M.; RODRIGUEZ, C. S.; DEWHURST, F. W. The effect of information Technologies on TQM: An initial analysis. International Journal of Production Economics, n. 89, p. 77-93, 2004.

MARTINS, C. F.; PRADA, C. A.; ABREU, A. F. DE. O papel da tecnologia da informação na condução do planejamento e controle da produção: um estudo de caso. GEPROS - Gestão da produção, operações e sistemas, ano 3, n. 1, p. 77-89, jan.-mar. 2008.

MCNAB, P. Convergência entre chão-de-fábrica e corporativo dá tonalidade da Automation Fair, Controle e Automação, ano 11, n. 143, p. 27, 2008.

MIGUEL, P. A. C. Estudo de caso na engenharia de produção: estruturação e recomendação para sua condução. Produção, v. 17, n. 1, p. 216-229, jan./abr. 2007.

MONTANARI, R. L.; PILATTI, L. A.; SCANDALARI, L. Equipes: motivação e comprometimento para implantação de tecnologias da informação no ambiente produtivo. In: II Encontro de Engenharia e Tecnologia dos Campos Gerais, Ponta Grossa. PPGEP - UTFPR, 2006.

MUNIZ JR, J. Modelo conceitual de gestão de produção baseado na gestão do conhecimento: um estudo no ambiente operário da indústria automotiva, tese, Guaratinguetá, UNESP, 2007.

MURBACK, F. G. R.; PAIVA, M. C.; CARVALHO, M. F. H. DE A influência da visibilidade de informações do chão-de-fábrica no desempenho da manufatura. In: XIII SIMPEP, Bauru, Nov. 2006.

NAKAJIMA, S. Introdução ao TPM - Total Productive Maintenance. São Paulo, IMC, 1989.

NEVES, J. M. S. DAS; SANTOS, F. C. A. Implantação de tecnologias de informação utilizadas na integração entre o chão-de-fábrica e os sistemas ERP, Controle e Automação, n. 143, p. 56-61, 2008.

OLIVEIRA, T. R. DE Da automação para a informação: como transformar sonho em realidade no meio de uma sopa de letras, Controle e Automação, ano 11, n. 143, p. 76-81, 2008. 


\section{Revista Produç @o}

PADRÃO JR, F.; ALVES FILHO, M.; LANNA, V. M. Implantação do MES em indústria de bebidas, Controle e Automação, p. 71-76, jul. 2002.

PITASSI, C.; LEITÃO, S. P. Tecnologia de informação e mudança: uma abordagem crítica. Revista da Administração de Empresas, São Paulo, v. 42, n. 2, p. 77-87, abr./jun. 2002.

SALATIEL, M.; SAMPAIO, G.; FONTES, A.; SANTANA, D. Desenvolvimento de sistema PIMS e MES para tratamento de efluentes, Controle e Automação, ano 11, n. 143, p. 82-85, 2008.

SEIXAS FILHO, C. TA, TI e TAI: uma questão de governança. Intech, São Paulo, n. 96, p. 18-23, 2007.

SHIRASUNA, M. MES: Situação presente e expectativa do futuro, Controle e Automação, ano 11, n. 143, p. 66-71, 2008.

SILVA JR, P. R. DE M. A pergunta certa, Controle e Automação, ano 11, n. 143, p. 47, 2008.

SOUZA, F. D. DE et al. Projeto boletim on-line: gerenciamento de informação da planta, Controle e Automação, ano 11, n. 143, p. 72-75, 2008.

VALLE, B. DE M. Tecnologia da informação no contexto organizacional. Ciência e Informação, Brasilia, v. 25, n. 1, 1996.

VAZ, M. M. Produtividade e flexibilidade com a intersecção do universo da automação com a informação, Controle e Automação, ano 11, n. 143, p. 62-64, 2008.

VINHAIS, J. A. Manufacturing execution system: the one-stop information source. Quality Digest, Chico, CA, Set. 98. Disponível em: < http://www.qualitydigest.com/sept98/html/mes.html $>$. Acesso em: abr. 2009.

WAGNER, A.; SPAREMBERGER, A; ZAMBERLAN, L.; BÜTTENBENDER, P. L.; WEIMANN, $\mathrm{L}$, J. Desenvolvimento da qualidade em atividades logísticas: um estudo de caso sobre as contribuições do QFD. In: XXVIII ENCONTRO NACIONAL E ENGENHARIA DE PRODUÇÃO, p. 1-13, Rio de Janeiro, out. 2008.

WAURZYNIAK, P. Automation integration, Manufacturing Engineering, n. 136, p. 105 - 116, mai. 2006. 